\title{
Avaliação Científica de Artigos 2011-2012
}

Alda Teixeira Gonçalves, Instituto de Segurança Social, I.P.

Ana Alexandre Fernandes, ISCSP-UTL

António Pedro Dores, CIES-IUL

David Ramos, Departamento de Geografía, Universidad de Salamanca

Isabel Guerra, DINÂMIA'CET-IUL

Jerome Krase, Brooklyn College, CUNY

Jesus Leal Maldonado, Universidad Complutense de Madrid

João Seixas, ICS-UL

João Figueira de Sousa, Departamento de Geografia e Planeamento Regional FCSH-UNL

Jordi Nofre Mateo, FCSH-UNL

José Manuel Henriques, DINÂMIA'CET-IUL

Luis Capucha, CIES-IUL

Luis Mendes, CEG-UL

Maria João Freitas, LNEC

Marluci Menezes, LNEC

Nuno Dias, DINÂMIA'CET-IUL

Paula André, DINÂMIA'CET-IUL

Paula Guerra, FL-UP

Paulo Almeida, CIES-IUL

Sérgio Caramelo, DINÂMIA'CET-IUL

Teresa Marat-Mendes, DINÂMIA'CET-IUL

Teresa Sá Marques, FLUP

Teresa Seabra, CIES-IUL 